\section{Stereotactic and Functional \\ Neurosurgery}

Received: December 21, 2011

Accepted after revision: June 11, 2012 Published online: August 23, 2012

\title{
DREZotomy in the Treatment of Cancer Pain: A Review
}

\author{
Nisha Gadgil Ashwin Viswanathan \\ Department of Neurosurgery, Baylor College of Medicine, Houston, Tex., USA
}

\section{Key Words}

Dorsal root entry zone $\cdot$ Cancer pain $\cdot$ Spinal cord

\begin{abstract}
Background: Cancer-related pain is a common problem that may be intractable by medical and neuromodulatory treatment. The dorsal root entry zone (DREZ) is a hyperactive focus in neuropathic pain syndromes, and DREZotomy has been used in selective cases of neuropathic cancer pain. $\mathbf{O b}$ jective: The aim of this study was to describe the technique of spinal DREZotomy in the treatment of cancer pain and review the relevant published literature. Methods: A PubMed database search for 'DREZ', 'dorsal root entry zone' and 'cancer', and a search of the references of these manuscripts, was undertaken. Results: 14 papers were identified and reviewed that described a total of 123 patients with cancer pain or radiation-induced pain who have been treated with DREZotomy. Though heterogeneous, these studies reported an overall favorable outcome in carefully selected patients with topographically limited pain syndromes. Conclusion: For patients with well-localized neuropathic cancer pain intractable to medical and first-line surgical management, DREZotomy is a viable treatment option. Further prospective studies are needed to evaluate the outcomes of this procedure.
\end{abstract}

Copyright ๑ 2012 S. Karger AG, Basel

\section{Introduction}

Chronic pain affects up to $75 \%$ of patients with advanced cancer [1]. Cancer pain can result from direct tumor invasion, malignant infiltration of nerves, and sequelae of cancer treatment including radiation-induced nerve injury, chemotherapy or postsurgical pain. The improved use of opioid and nonopioid analgesics, along with the use of neuromodulation via intrathecal drug delivery and neurostimulation, has augmented the ability to treat refractory cancer pain effectively. However, ablative techniques for the management of cancer pain remain important in the subgroup of patients whose pain has proven intractable to these therapies, or in whom the implantation of a medical device is not feasible.

A recent review of destructive procedures in the treatment of cancer pain highlights the lack of class I and II evidence for these procedures [2]. However, the absence of strong evidence is not indicative of a lack of efficacy. The greatest experience with the use of destructive techniques for the management of cancer pain is with cordotomy, for which the outcomes of more than 3,500 patients have been reported in the literature. A recent prospective series of 41 patients who underwent cervical cordotomy for cancer pain demonstrated excellent lasting results with $80 \%$ of patients experiencing pain relief at the 6-month follow-up [2].

\section{KARGER}

Fax +41613061234 E-Mail karger@karger.ch www.karger.com
Assist. Prof. Ashwin Viswanathan, MD

Department of Neurosurgery

Baylor College of Medicine, 1709 Dryden, Suite 750

Houston, TX 77030 (USA)

Tel. +1 713798 4696, E-Mail ashwinv@ bcm.edu 
The high monetary and time investments needed for intrathecal drug delivery, along with the increased safety and accuracy of modern neurosurgery, are compelling reasons for the continued use of ablative techniques in the management of cancer pain. Several case series have reported the use of dorsal root entry zone (DREZ) lesioning in the management of cancer pain. However, a review of outcomes does not exist in the literature. In this review, we evaluate the current evidence for the benefits and limitations of spinal DREZotomy for cancer pain.

\section{DREZotomy Procedure}

The DREZ is comprised of three structures including the central portion of the dorsal rootlets, the medial portion of Lissauer's tract, and the dorsal layers of the dorsal horn of the spinal cord. The DREZ serves to integrate and modulate incoming nociceptive signals from the peripheral nervous system. Before synapsing in the spinal cord, nociceptive inputs enter through the lateral portion of the dorsal rootlets and travel rostrocadually for several segments in a thin tract of axons known as Lissauer's tract, which caps the dorsal horn. Lissauers's tract either increases or inhibits incoming pain signals before they synapse in Rexed laminae 1, 2 and 5, thus modulating pain. The detailed anatomy of this circuit has been previously described [3-6].

In 1968, Loeser et al. [7] proposed that neuropathic pain is associated with hyperactivity of dorsal horn neurons in the human spinal cord through intraoperative recordings obtained with glass capillary micropipettes. Subsequent electrophysiological studies in humans have confirmed the hyperactivity of deafferentated neurons in chronic pain conditions [8-10]. Based on these and other studies, DREZotomy seeks to treat chronic pain by selectively destroying the lateral portions of the dorsal rootlets, the hyperactive neurons of the dorsal horn, and the excitatory portion of Lissauer's tract [11]. A number of different techniques have been used to accomplish this goal including microsurgical, radiofrequency, ultrasonic and laser ablation [6, 12-15]. In comparison to DREZ lesioning for brachial plexus avulsion, DREZotomy for cancer pain requires elevation of the dorsal rootlets to allow lesioning in the ventrolateral portion of the root entry zone. Online supplement video 1 (for all suppl. material, see www.karger.com/doi/10.1159/000341072) illustrates microsurgical DREZotomy using bipolar coagulation, as described by Sindou et al. [16]. Most experienced clinicians advocate a hemilaminectomy approach with conservation of the spinous processes to preserve stability and limit postoperative pain.

DREZotomy for Cancer Pain

\section{Application of DREZotomy}

In 1972, Sindou et al. [17] published the first case of microsurgical lesioning of the DREZ in a patient suffering from neuropathic pain related to a Pancoast tumor that had infiltrated the brachial plexus. Several years later, Nashold et al. [18] used a radiofrequency electrode to similarly lesion the DREZ in 4 patients with brachial plexus avulsion injuries. Subsequently, DREZotomy has been applied in the treatment of a number of intractable pain states including brachial plexus avulsion, postherpetic neuralgia, spinal cord injury, hyperspasticity and others. The largest and most successful experience with DREZotomy has been in the treatment of brachial plexus avulsion. In a recent prospective series of DREZotomy for brachial plexus avulsion, $76.9 \%$ of patients had good or excellent pain relief following surgery [16]. At 10 years postoperatively, $41.1 \%$ of patients had lasting pain control. The relief from the paroxysmal shooting pains was found to be significantly more durable than the relief from the continuous burning pains $[11,16]$. Unlike myelotomy and cordotomy, DREZotomy is not effective in relieving pain below the level of the lesion [11, 19-21].

A number of case series have been published describing experience with DREZotomy; however, only a limited number of patients in aggregate with cancer pain have been reported. It is important to define the role and efficacy of DREZotomy in the management of cancer pain. This consideration prompted the present review of DREZotomy for cancer pain.

\section{Methods}

A search of the Pubmed database was performed to identify all articles discussing DREZotomy in cancer patients. We searched for articles with the following search terms: 'DREZ', 'dorsal root entry zone' and 'cancer'. We then searched all references in these manuscripts. Only articles written in English were reviewed. Fourteen articles were identified which provided data for patients treated with DREZotomy for cancer pain. When a single center had provided more than one report of their results, the longest follow-up was used for the analysis of outcomes. Care was taken to report the data of a given patient only once.

\section{Results}

One of the earliest DREZotomy studies by Nashold and Ostdahl [12] in 1979, consisting primarily of patients with brachial plexus avulsions, included 1 patient with a giant cell tumor of the sacrum who experienced excellent relief following bilateral DREZotomy. Another study by 
Table 1. DREZotomy for cancer pain

\begin{tabular}{|c|c|c|c|c|}
\hline Paper/year & Diagnosis & Patients & Follow-up & Outcome \\
\hline $\begin{array}{l}\text { Nashold and Ostdahl } \\
{[12], 1979}\end{array}$ & Giant cell tumor of sacrum & 1 & 8 months & Excellent relief \\
\hline $\begin{array}{l}\text { Nashold and Bullitt } \\
{[22], 1981}\end{array}$ & Conus tumor & 1 & 14 months & Excellent relief \\
\hline $\begin{array}{l}\text { Sindou and Lapras } \\
{[23], 1982}\end{array}$ & Pancoast tumor & 13 & $1-30$ months & 10 of 11 with good result, 2 deaths \\
\hline $\begin{array}{l}\text { Samii and Moringlane } \\
{[29], 1984}\end{array}$ & Breast cancer & 2 & n.s. & 1 with very good result, 1 with fair result \\
\hline Saris et al. [30], 1985 & Amputation due to cancer & 2 & n.s. & Both poor outcomes \\
\hline $\begin{array}{l}\text { Friedman and Nashold } \\
{[19], 1986}\end{array}$ & Tumor & 2 & n.s. & n.s. \\
\hline $\begin{array}{l}\text { Powers et al. [31], } \\
1988\end{array}$ & Cancer pain & 3 & n.s. & All with good pain relief \\
\hline $\begin{array}{l}\text { Esposito et al. [27], } \\
1988\end{array}$ & Cancer pain & 8 & n.s. & Good result \\
\hline $\begin{array}{l}\text { Kumagai et al. [28], } \\
1992\end{array}$ & Uterine cancer & 1 & 2 months & $50 \%$ subjective pain improvement \\
\hline $\begin{array}{l}\text { Zeidman et al. [26], } \\
1993\end{array}$ & Radiation-induced brachial plexopathy & 2 & 29-48 months & 2 with good result \\
\hline Sindou [4], 1995 & $\begin{array}{l}\text { Cancer pain - cervical } \\
\text { Cancer pain lumbar or sacral }\end{array}$ & $\begin{array}{l}46 \\
35\end{array}$ & 1 month to 4 years & $\begin{array}{l}87 \% \text { with good result } \\
78 \% \text { with good result }\end{array}$ \\
\hline Rath et al. [20], 1996 & $\begin{array}{l}\text { Radiation-induced } \\
\text { Breast cancer }\end{array}$ & $\begin{array}{l}2 \\
1\end{array}$ & $\begin{array}{l}6-8 \text { months } \\
18 \text { days }\end{array}$ & $\begin{array}{l}1 \text { pain free, } 1 \text { with persistent pain } \\
\text { Died postoperatively of pulmonary embolus }\end{array}$ \\
\hline $\begin{array}{l}\text { Teixeira et al. [25], } \\
2007\end{array}$ & Radiation-induced brachial plexopathy & 7 & $2-36$ months & $\begin{array}{l}6 \text { with complete relief ( } 1 \text { after reoperation), } 1 \text { with partial } \\
\text { relief }\end{array}$ \\
\hline $\begin{array}{l}\text { Ruiz-Juretschke et al. } \\
{[24], 2011}\end{array}$ & Neoplastic infiltration of brachial plexus & 3 & n.s. & 1 with moderate result, 2 with poor result \\
\hline $\begin{array}{l}\text { Kanpolat et al. [5], } \\
2008\end{array}$ & Tumor infiltration & 7 & n.s. & $60 \%$ with no pain or partial satisfactory pain relief \\
\hline
\end{tabular}

the authors shortly afterward included a paraplegic patient with central pain resulting from a tumor involving the conus who experienced excellent pain relief following DREZotomy [22]. The authors concluded that the procedure may potentially be beneficial in chronic pain from etiologies other than root avulsion.

The largest evidence supporting the use of the DREZotomy in cancer patients comes from Sindou's experience with the procedure. In 1982, the author reported a series of 13 patients with Pancoast tumors treated with microsurgical DREZotomy [23]. Two patients died in the postoperative period, and of the 11 survivors, 10 experienced good results. The author published another series documenting a 20-year experience with microsurgical
DREZotomy, from 1972 onwards [4]. In this series of 367 patients, 81 were treated for cancer pain; it is not clear whether this group includes patients in the previously mentioned study. A good result ( $>75 \%$ pain relief) was obtained in $87 \%$ of patients operated at the cervicothoracic level and $78 \%$ of the patients operated at the lumbosacral level. The median postoperative survival was 13 months. The authors report 2 postoperative surgical site infections and 2 patients in whom surgery was thought to precipitate death. Detailed descriptions of patient characteristics and patient selection are not provided unfortunately. However, the authors suggest that good candidates for DREZotomy are patients with 'topographically limited pain caused by local lesions' as seen in Pancoast tu- 
mor, invasion of the thoracic or abdominal wall, or limited involvement of the lumbosacral nerves. It is important to note that the authors report a similar efficacy of the procedure in patients operated for neurogenic pain (87\%), though with fewer serious adverse events. These results suggest that in properly selected patients, DREZotomy can be effective in treating cancer pain.

The remainder of the published experience of DREZotomy to treat cancer pain comes from small series that include a limited number of patients with cancer pain (table 1). The outcomes for these small case series are mixed. Kanpolat et al. [5] used a radiofrequency technique in treating 7 cancer patients with predominantly neuropathic cancer pain, and $60 \%$ of patients had either no pain or partial satisfactory pain relief postoperatively. In contrast to these good outcomes, Ruiz-Juretschke et al. [24] reported the results in 3 patients with neoplastic infiltration of the brachial plexus who underwent DREZotomy. Their results were discouraging, with no immediate or long-term pain reduction in 2 patients, and moderate pain reduction in the third. The pain relief achieved in this final patient became reduced by the longer-term follow-up [24].

A small number of studies have investigated the use of DREZotomy to treat radiation-induced plexopathy, a deafferentation pain syndrome associated with radiation therapy. Radiation-induced plexopathy is often resistant to both medical management and peripheral ablative procedures. The largest experience was shared by Teixeira et al. [25], who reported complete resolution of pain in 5 of 6 patients with a median follow-up of 12 months. All patients had previously failed medical and some had failed surgical therapy; preoperative pain rating was between 8 and 10 on the visual analogue scale [25]. Two other studies each included 2 patients with radiation-induced plexopathy: 3 became pain free and 1 had recurrence of pain 8 months after the procedure $[20,26]$. Though these studies are small, the results hold great promise for an incapacitating condition which otherwise has no effective treatment.

The heterogeneity of the cancer patient population and surgical techniques used in these series makes outcome analysis for DREZotomy difficult.

\section{Discussion}

Spinal neuroablative procedures for pain management are technically demanding procedures and carry the risk of neurological deficit. A large experience has demon- strated the efficacy of DREZotomy in the treatment of pain after brachial plexus avulsion. The application of DREZotomy to cancer pain has yielded good results by Sindou, Kanpolat and Teixeira, whose experience with the procedure is extensive. Other less favorable reports of DREZotomy prevent a strong conclusion regarding the efficacy of DREZ lesioning for cancer pain. However, the varying postoperative outcomes may be related to variations in surgical technique and surgeon experience.

There are several surgical considerations when performing DREZotomy for cancer pain as compared to brachial plexus avulsion. Because the nerve rootlets are intact and there are fewer atrophic and gliotic changes which can distort the anatomy, accurate identification of the DREZ is less challenging, potentially minimizing inadvertent lesioning of adjacent structures. However, the dorsal rootlets must be carefully elevated and the lesion made in the proper trajectory. A wide variety of techniques have been explored to create lesions in the DREZ. Sindou [4] uses bipolar microcoagulation, which is the technique preferred at our institution. The most commonly used technique in the series reviewed is radiofrequency coagulation; other techniques such as laser-produced lesions [31] have been explored by some. An analysis of which technique produces the best result is not possible given the limited data available, and ultimately the choice should be based on the comfort and experience of the surgeon.

There is no question that the management of cancer pain is a multidisciplinary effort. Over the last two decades, the ability to manage pain with opioid and nonopioid analgesics has increased tremendously, and the use of intraspinal opioids has also improved quality of life for cancer patients. Despite this, there are patients who do not experience satisfactory pain relief with multimodal therapy, and in these patients neuroablative techniques are valuable. Percutaneous cordotomy can be performed with minimal morbidity to the patient. Consequently, this is often the first-line therapy for unilateral pain. In patients with refractory predominantly neuropathic pain in a topographically limited distribution, however, DREZotomy may be a very effective option.

Though the efficacy of DREZotomy may diminish with time, this is often not a major concern in the cancer population where achieving a 6 -month significant pain reduction can dramatically alter quality of life. The approach adopted by Kanpolat et al. [5] is one we favor at our institution. For patients with medically intractable pain who either have not responded to intrathecal opioids, or the implantation of a medical device is not appropriate, we use percutaneous cordotomy as a first-line therapy for in- 
tractable nociceptive cancer pain and DREZotomy as a second treatment option. For patients with predominantly neuropathic pain, however, DREZotomy should be considered before cordotomy if the patient can tolerate the operation and has a relatively long life expectancy.

\section{Conclusions}

This review of the published experience with DREZotomy for cancer pain supports the judicious use of the procedure for carefully selected patients with cancer pain or radiation-induced pain. Spinal DREZotomy should be reserved for patients with malignant lesions producing well-localized, segmental neuropathic pain. Further studies are required to more clearly define the benefit of DREZotomy in cancer patients. An appropriate initial prospective study to evaluate DREZotomy for cancer pain might focus on two pathologies in which the best results have been reported - Pancoast tumor and radiation-induced plexopathy. Should carefully documented outcomes demonstrate efficacy with an acceptable morbidity, broader patient diagnoses and conditions could be explored.

\section{References}

$\checkmark 1$ Paice JA, Ferrell B: The management of cancer pain. CA Cancer J Clin 2011;61:157-182.

$\checkmark 2$ Raslan AM, Cetas JS, McCartney S, Burchiel $\mathrm{K}$ : Destructive procedures for control of cancer pain: the case for cordotomy. J Neurosurg 2011;114:155-170.

-3 Sindou M, Quoex C, Baleydier C: Fiber organization at the posterior spinal cord-rootlet junction in man. J Comp Neurol 1974;153: 15-26.

4 Sindou M: Microsurgical DREZotomy (MDT) for pain, spasticity, and hyperactive bladder: a 20-year experience. Acta Neurochir 1995;137:1-5.

5 Kanpolat Y, Tuna H, Bozkurt M, Elhan A: Spinal and nucleus caudalis dorsal root entry zone operations for chronic pain. Neurosurgery 2008;62:ONS235-ONS244.

6 Sindou M, Daher A: Spinal cord ablation procedures for pain; in Dubner R, et al (eds): Proceedings of the Vth World Congress on Pain. Pain Research and Clinical Management. Amsterdam, Elsevier, 1988, vol 3, pp 477-495.

$\checkmark 7$ Loeser JD, Ward AA, White LE: Chronic deafferentation of human spinal cord neurons. J Neurosurg 1968;29:48-50.

$>8$ Guenot M, Hupe JM, Mertens P, Ainsworth A, Bullier J, Sindou M: A new type of microelectrode for obtaining unitary recordings in the human spinal cord. J Neurosurg 1999;91: 25-32.

$\checkmark 9$ Guenot M, Bullier J, Rospars J, Lansky P, Mertens P, Sindou M: Single-unit analysis of the spinal dorsal horn in patients with neuropathic pain. J Clin Neurophysiol 2003;20: 143-150.

10 Jeanmonod D, Sindou M, Magnin M, Baudet $\mathrm{M}$ : Intra-operative unit recordings in the human dorsal horn with a simplified floating microelectrode. Electroencephalogr Clin Neurophysiol 1989;72:450-454.

-11 Sindou M, Mertens P, Wael M: Microsurgical DREZotomy for pain due to spinal cord and/ or cauda equina injuries: long-term results in a series of 44 patients. Pain 2001;92:159-171.
12 Nashold BS, Ostdahl RH: Dorsal root entry zone lesions for pain relief. J Neurosurg 1979 51:59-69.

-13 Sindou M, Jeanmonod D: Microsurgical DREZ-otomy for the treatment of spasticity and pain in the lower limbs. Neurosurgery 1989;24:655-670.

14 Dreval ON: Ultrasonic DREZ-operations for treatment of pain due to brachial plexus avulsion. Acta Neurochir 1993;122:76-81.

15 Young RF: Clinical experience with radiofrequency and laser DREZ lesions. J Neurosurg 1990;72:715-720.

-16 Sindou MP, Blondet E, Emery E, Mertens P: Microsurgical lesioning in the dorsal root entry zone for pain due to brachial plexus avulsion: a prospective series of 55 patients J Neurosurg 2005;102:1018-1028.

- 17 Sindou M, Fischer G,Goutelle A, Schott B, Mansuy L: Selective surgery of posterior nerve roots: first results of surgery for pain. Neurochirurgie 1974;20:391-408.

18 Nashold BS, Urban B, Zorub DS: Phantom relief by focal destruction of substantia gelatinosa of Rolando; in Bonica JJ, Albe-Fessard DD (eds): Advances in Pain Research and Therapy. New York, Raven Press, 1976, vol 1, pp 959-963.

19 Friedman AH, Nashold BS: DREZ lesions for relief of pain related to spinal cord injury. J Neurosurg 1986;65:465-479.

20 Rath SA, Braun V, Soliman N, Antoniadis G, Richter HP: Results of DREZ coagulations for pain related to plexus lesions, spinal cord injuries and postherpetic neuralgia. Acta Neurochir 1996;138:364-369.

21 Spaic M, Petkovic S, Tadic R, Minic L: DREZ surgery on conus medullaris (after failed implantation of vascular omental graft) for treating chronic pain due to spine (gunshot) injuries. Acta Neurochir 1999;141:1309-1312.
22 Nashold BS, Bullitt E: Dorsal root entry zone lesions to control central pain in paraplegics. J Neurosurg 1981;55:414-419.

23 Sindou M, Lapras C: Neurosurgical treatment of pain in the Pancoast-Tobias syndrome: selective posterior rhizotomy and open antero-lateral $\mathrm{C}_{2}$-cordotomy; in Bonica J, et al (eds): Advances in Pain Research and Therapy: Management of Superior Pulmonary Sulcus Syndrome. New York, Raven Press, 1982, vol 4, pp 199-209.

24 Ruiz-Juretschke F, Garcia-Salazar F, GarciaLeal R, Fernandez-Carballal C, Iza B, Garbizu JM, Garcia-Duque S, Panadero T: Treatment of neuropathic deafferentation pain using DREZ lesions: long-term results. Neurologia 2011;26:26-31.

-25 Teixeira MJ, Fonoff ET, Montenegro MC: Dorsal root entry zone lesions for treatment of pain related to radiation-induced plexopathy. Spine 2007;32:E316-E319.

26 Zeidman SM, Rossitch EJ, Nashold BS: Dorsal root entry zone lesions in the treatment of pain related to radiation-induced brachial plexopathy. J Spinal Disord 1993;6:44-47.

27 Esposito S, Delitala A, Nardi PV: Microsurgical DREZ-lesion in the treatment of deafferentation pain. J Neurosurg Sci 1998;32: 113-115.

28 Kumagai Y, Shimoji K, Honma T, Uchiyama S, Ishijima B, Hokari T, Fujioka H, Fukuda S, Ohama E: Problems related to dorsal root entry zone lesions. Acta Neurochir 1992;115: 71-78.

29 Samii M, Moringlane JR: Thermocoagulation of the dorsal root entry zone for the treatment of intractable pain. Neurosurgery 1984; 15:953-955.

30 Saris SC, Iacono RP, Nashold BS: Dorsal root entry zone lesions for post-amputation pain. J Neurosurg 1985;62:72-76.

-31 Powers SK, Barbaro NM, Levy RM: Pain control with laser-produced dorsal root entry zone lesions. Appl Neurophysiol 1988;51: 243-254. 